\title{
Substance abuse effects on urinary tract: methamphetamine and ketamine
}

\author{
CH Yee *, CF Ng, YL Hong, PT Lai, YH Tam
}

\section{A B S T R A C T}

Introduction: Ketamine is known to cause urinary tract dysfunction. Recently, methamphetamine (MA) abuse has become a growing problem in Asia. We investigated the symptomatology and voiding function in patients who abused MA and ketamine and compared their urinary tract toxicity profiles.

Methods: In the period of 23 months from 1 October 2016, all consecutive new cases of patients presenting with MA- or ketamine-related urological disorder were recruited into a prospective cohort. Polysubstance abuse patients were excluded. Data were analysed by comparison between patients with ketamine abuse and MA abuse. Basic demographic data and initial symptomatology were recorded, and questionnaires on urinary symptoms and the Montreal Cognitive Assessment (MoCA) were used as assessment tools.

Results: Thirty-eight patients were included for analysis. There was a statistically significant difference in mean age between patients with MA and ketamine abuse $(27.2 \pm 7.2$ years and $31.6 \pm 4.8$ years, respectively, $\mathrm{P}=0.011$ ). Urinary frequency was

This article was published on 4 Dec 2019 at www.hkmj.org. the most common urological symptom in our cohort of patients. There was a significant difference in the

$\mathrm{P}=0.026)$ and a significant trend in the difference in hesitancy (ketamine 4.3\%, MA 26.7\%, $\mathrm{P}=0.069$ ). Overall, questionnaires assessing urinary storage symptoms and voiding symptoms did not find a statistically significant difference between the two groups. The MoCA revealed that both groups had cognitive impairment (ketamine 24.8 \pm 2.5 , MA 23.6 $\pm 2.9, \mathrm{P}=0.298$ ).

Conclusions: Abuse of MA caused urinary tract dysfunction, predominantly storage symptoms. Compared with ketamine abuse, MA abuse was not commonly associated with dysuria or pelvic pain.

\section{Hong Kong Med J 2019;25:438-43}

https://doi.org/10.12809/hkmj198154

\author{
${ }^{1} \mathrm{CH}$ Yee *, MB, BS, FRCS (Edin) \\ ${ }^{1} \mathrm{CF}$ Ng, MB, ChB, FRCS (Edin) \\ ${ }^{2}$ YL Hong, MSc \\ 1 PT Lai, BN \\ ${ }^{2}$ YH Tam, MB, ChB, FRCS (Edin) \\ Department of Surgery, SH Ho Urology Centre, The Chinese University \\ of Hong Kong, Shatin, Hong Kong \\ 2 Department of Surgery, The Chinese University of Hong Kong, Shatin, \\ Hong Kong
}

* Corresponding author: yeechihang@surgery.cuhk.edu.hk

New knowledge added by this study

- Conventionally, methamphetamine has mainly been implicated for its neurological impact. Our study illustrated the impact of methamphetamine on the urinary tract, ie, an increase in storage symptoms.

- Cognitive impairment from ketamine abuse was also documented in our study with a valid assessment.

Implications for clinical practice or policy

- Management of methamphetamine and ketamine abuse should involve multiple disciplines to improve the comprehensiveness of assessment and treatment.

\section{Introduction}

Both the range of available drugs and the scope of drug markets are expanding and diversifying. Abuse of substances such as amphetamine-type stimulants, cannabis, and cocaine are major global health concerns. According to World Health Organization statistics, the number of cannabis users increased from 183 million in 2015 to 192 million in 2016 worldwide, whereas 34 million people abuse amphetamines and prescription stimulants. ${ }^{1}$

While the spectrum of substance abuse can be wide, many forms of illicit drug use inevitably induce toxicity and detrimental effects on the urinary tract.
Smoking cannabis was found to have a significant association with bladder cancer in a hospital-based case-control study, ${ }^{2}$ attributed to the common carcinogens present in cannabis and tobacco smoke. ${ }^{3}$ Acute renal infarction has been observed in patients who used cocaine. ${ }^{4}$ Ketamine has received particular attention in the past few years for its impacts on both the upper and lower urinary tract. ${ }^{5}$ It has been one of the most commonly abused substances by teenagers since 2005 in Asian cities such as Hong Kong. ${ }^{6}$

In recent years, methamphetamine (MA) abuse has also become a serious and growing problem in Asia. ${ }^{7}$ The proportion of people abusing 
MA increased from $28.8 \%$ to $75.1 \%$ over a span of 5 years in China. ${ }^{8}$ Japan has seen its third epidemic of MA abuse since $1995 .{ }^{9}$ South Korea has also had an increase in psychotropic drug abuse, predominantly MA, from 7919 people in 2014 to 11396 in 2016. ${ }^{10}$ In Hong Kong, $25.9 \%$ of people who abused drugs had exposure to amphetamine-type psychotropic substances in 2017. ${ }^{11}$ While the psychological and neurological effects of MA have been widely discussed, the urological aspects of the drug's sideeffects have not yet been well documented in the literature. We investigated the symptomatology and voiding function in a cohort of patients who abused the two most common psychotropic substances in our locality, namely MA and ketamine, and compared their urinary tract toxicity profiles.

\section{Methods}

In the period of 23 months from 1 October 2016, all consecutive new cases of patients who attended our centre for MA- or ketamine-related urological disorders were seen in a dedicated clinic and were recruited into a prospective cohort. Ethics committee approval was granted for the study (CREC Ref CRE2011.454). Written informed consent was given by all participants before entering the study.

Basic demographic data were recorded before clinic attendance, including age, sex, employment status, drinking habits, and smoking history. Habits of substance abuse were characterised. Serum creatinine levels, urine microscopy and culture, and uroflowmetry were measured. Initial symptomatology enquiry included the presence and characteristics of frequency, urgency, suprapubic pain, haematuria, hesitancy, intermittency, and incomplete emptying. Functional bladder capacity was calculated by adding the voided volume to post-void urine residuals during the uroflowmetry assessment. Urological symptoms were assessed with the International Prostate Symptom Score (IPSS) or the Overactive Bladder Symptom Score (OABSS). ${ }^{12}$ The International Index of Erectile Function (IIEF) was used to assess sexual function in male respondents who were sexually active in the preceding 4 weeks. Another component of symptom assessment was the Pelvic Pain and Urgency/Frequency (PUF) patient symptom scale. The Chinese version of the PUF symptom scale is a validated assessment tool for cystitis. ${ }^{13}$ For cognitive dysfunction, we employed the Montreal Cognitive Assessment (MoCA) as an assessment tool. Chu et $\mathrm{al}^{14}$ proved the validity and reliability of the Cantonese Chinese MoCA as a brief screening tool for cognitive impairment.

Polysubstance abuse patients were excluded. Data were analysed by comparison between two groups of patients, namely those with ketamine abuse only and those with MA abuse only. Descriptive

\section{濫用甲基安非他命和氯胺酮對泌尿系統的影響}

\author{
余知行、吳志輝、匡若琳、黎珮德、譚煜謙
}

引言 : 眾所周知, 氯胺酮可引致泌尿系統功能失調。濫用甲基安非他 命近年成為亞洲日益嚴重的問題。我們檢視濫用甲基安非他命和氯胺 酮病人的症狀及排尿功能和比較他們的泌尿系統毒理資料

方法：由2016年1月起的23個月期間，所有與甲基安非他命或氯胺酮 有關的泌尿系統失調新症患者都被納入此前瞻性隊列, 但不包括濫用 多種藥物的病人。比較濫用氯胺酮及甲基安非他命病人的數據來進行 數據分析。收集了基本個人資料及初始症狀, 使用有關泌尿症狀的問 卷和蒙特利爾認知評估香港版作為評估工具。

結果：對38名病人的資料進行分析。濫用甲基安非他命及氯胺酮病 人的平均年齡有統計顯著差異 ( 分別是 $27.2 \pm 7.2$ 歲及 $31.6 \pm 4.8$ 歲, $\mathrm{P}=0.011) \circ$ 尿頻是此隊列病人中最常見的症狀。排尿困難的患病率 有統計顯著差異（氯胺酮 $43.5 \%$ 比甲基安非他命 $6.7 \%, \mathrm{P}=0.026$ ） 兩組的排尿費力也有分別（氯胺酮 $4.3 \%$ 比甲基安非他命 $26.7 \%$, $\mathrm{P}=0.069$ ）。整體而言, 兩組之間問卷評估得出的泌尿儲存及排尿症 狀沒有統計顯著差異。蒙特利爾認知評估香港版的結果表示兩組皆有 認知受損（氯胺酮 $24.8 \pm 2.5$ 比甲基安非他命 $23.6 \pm 2.9, \mathrm{P}=0.298$ ）。

結論：濫用甲基安非他命可引致泌尿系統失調, 主要是儲存功能出現 問題。與濫用氯胺酮相比, 排尿困難或髖部痛楚較少見於濫用甲基安 非他命的病人。

TABLE I. Demographics of patients $(n=38)^{*}$

\begin{tabular}{|c|c|c|c|}
\hline Demographics & Ket only & MA only & $P$ value \\
\hline No. of patients & $23(60.5 \%)$ & 15 (39.5\%) & \\
\hline Sex & & & 0.740 \\
\hline Male & 12 & 7 & \\
\hline Female & 11 & 8 & \\
\hline Age (years) & $31.6 \pm 4.8$ & $27.2 \pm 7.2$ & $0.011 \dagger$ \\
\hline $\begin{array}{l}\text { Active user on } \\
\text { presentation }\end{array}$ & 7 & 4 & $0.802 \ddagger$ \\
\hline $\begin{array}{l}\text { Duration of abuse } \\
\text { (months) }\end{array}$ & $124.4 \pm 40.0$ & $57.7 \pm 45.4$ & $<0.001 \uparrow$ \\
\hline Smoking status & & & $0.152 \ddagger$ \\
\hline Non-smoker & 3 & 1 & \\
\hline Smoker & 18 & 9 & \\
\hline Ex-smoker & 2 & 5 & \\
\hline Drinking habits & & & $0.270 \ddagger$ \\
\hline Non-drinker & 15 & 8 & \\
\hline 0-4 drinks/month & 3 & 2 & \\
\hline $\begin{array}{l}\text { Non-daily drinker, } \\
>4 \text { drinks/month }\end{array}$ & 5 & 3 & \\
\hline Daily drinking & 0 & 2 & \\
\hline Employment & & & $0.097 \ddagger$ \\
\hline Unemployed & 9 & 10 & \\
\hline Employed & 14 & 5 & \\
\hline
\end{tabular}

Abbreviations: Ket = ketamine; $\mathrm{MA}=$ methamphetamine

* Data are shown as No. (\%) or mean \pm standard deviation

† Mann-Whitney $U$ test

Chi squared test 
TABLE 2. Presenting symptoms of patients

\begin{tabular}{|c|c|c|c|}
\hline & $\begin{array}{c}\text { Ket only } \\
(n=23)\end{array}$ & $\begin{array}{c}\text { MA only } \\
(n=15)\end{array}$ & $P$ value \\
\hline Symptom(s) duration (months) & $45.7 \pm 31.2$ & $41.7 \pm 47.5$ & $0.191^{*}$ \\
\hline \multicolumn{4}{|l|}{ Presenting symptom } \\
\hline Frequency & & & $0.722 \dagger$ \\
\hline Yes & 17 (73.9\%) & $10(66.7 \%)$ & \\
\hline No & $6(26.1 \%)$ & $5(33.3 \%)$ & \\
\hline Urgency & & & $0.722 \dagger$ \\
\hline Yes & $6(26.1 \%)$ & $5(33.3 \%)$ & \\
\hline No & 17 (73.9\%) & $10(66.7 \%)$ & \\
\hline Dysuria & & & $0.026 \dagger$ \\
\hline Yes & $10(43.5 \%)$ & $1(6.7 \%)$ & \\
\hline No & $13(56.5 \%)$ & 14 (93.3\%) & \\
\hline Suprapubic pain & & & $0.209 \dagger$ \\
\hline Yes & $6(26.1 \%)$ & $1(6.7 \%)$ & \\
\hline No & 17 (73.9\%) & $14(93.3 \%)$ & \\
\hline Haematuria & & & $0.509+$ \\
\hline Yes & $2(8.7 \%)$ & 0 & \\
\hline No & $21(91.3 \%)$ & $15(100.0 \%)$ & \\
\hline Hesitancy & & & $0.069+$ \\
\hline Yes & $1(4.3 \%)$ & $4(26.7 \%)$ & \\
\hline No & $22(95.7 \%)$ & $11(73.3 \%)$ & \\
\hline Intermittent stream & & & $1.000 \dagger$ \\
\hline Yes & $1(5.9 \%)$ & $1(10.0 \%)$ & \\
\hline No & $16(94.1 \%)$ & 9 (90.0\%) & \\
\hline Sensation of incomplete emptying & & & $0.743 \dagger$ \\
\hline Yes & $9(39.1 \%)$ & $7(46.7 \%)$ & \\
\hline No & $14(60.9 \%)$ & $8(53.3 \%)$ & \\
\hline
\end{tabular}

Abbreviations: Ket = ketamine; $M A$ = methamphetamine

* Mann-Whitney $U$ test

† Fisher's exact test between the two groups of patients with MA and ketamine abuse $(27.2 \pm 7.2$ years and $31.6 \pm 4.8$ years, respectively, $\mathrm{P}=0.011)$. Most patients were not active substance abusers upon presentation to the clinic. While all patients had a history of substance abuse, only two (5.3\%) patients were consuming alcohol on a daily basis.

Urinary frequency was the single most common urological symptom in our patient cohort. Regardless of whether the patient was consuming ketamine alone, MA alone, or a combination of ketamine and MA, urinary frequency was found in $71.1 \%$ of the patients, with no statistically significant differences between these groups (Table 2). Other symptoms that shared similar distributions between both groups were urgency, suprapubic pain, intermittent stream, and sensation of incomplete emptying. There was a statistically significant difference in the prevalence of dysuria between the two groups (ketamine $43.5 \%$, MA $6.7 \%, \mathrm{P}=0.026$ ). A trend was observed in the difference in prevalence of hesitancy (ketamine 4.3\%, MA 26.7\%, $\mathrm{P}=0.069$ ).

To summarise the results of questionnaires that assess urinary storage symptoms and voiding symptoms as a whole, neither OABSS nor IPSS revealed a statistically significant difference between the two patient groups (Table 3 ). The mean IPSS score of the ketamine only group was $20.9 \pm 8.1$, falling into the severe symptom category, whereas that of the MA only group was $16.1 \pm 8.9$, falling into the moderate symptom group. No significant differences in maximal voiding velocity, voided volume, postvoid residual, or bladder capacity were observed between the two groups. Similarly, no significant difference was observed in sexual function between the male patients of these three groups, as assessed by IIEF.

Pelvic pain assessment with the PUF symptom scale revealed higher scores in the ketamine group, especially in the Bother score domain (ketamine 6.7 \pm 2.9 , MA $4.7 \pm 2.5, \mathrm{P}=0.036$ ). Cognitive assessment using MoCA revealed that both groups had impairment, but there was no significant difference between the MA group and the ketamine group (ketamine $24.8 \pm 2.5$, MA $23.6 \pm 2.9, \mathrm{P}=0.298$ ). Serum creatinine did not differ significantly between the groups (ketamine $88.48 \pm 55.44$, MA $66.83 \pm$ 16.92, $\mathrm{P}=0.138)$.

\section{Discussion}

Substance abuse is a significant public health problem, with approximately $5.2 \%$ of the world population aged between 15 and 64 years having used illicit drugs at least once in the previous year. ${ }^{1}$ Southeast and East Asia have been a global hub for MA production and trafficking over the past decades, and its abuse is common in areas of South Korea, China, Taiwan, Japan, the Golden Triangle, 
and Iran. ${ }^{10}$ Psychotropic substance abuse is the most common form of drug abuse in Hong Kong, and since 2015, MA has taken over ketamine's spot as the leading drug of abuse among all psychotropic substances. ${ }^{11}$ As MA has become the new trendy drug of abuse, and most drug abusers are young and had their first drug exposure at an early age, this can account for our finding that patients who used MA had a lower mean age than patients who used ketamine in the cohort (Table 1).

Methamphetamine belongs to the class of amphetamines that also includes other drugs such as MDMA (3,4-methylenedioxy-Nmethylamphetamine). The stimulant, euphoric, anorectic, empathogenic, entactogenic, and hallucinogenic properties of MA drive its popularity for abuse. Kolbrich et $\mathrm{al}^{15}$ demonstrated the fast, widespread, and long-lasting distribution of MA in the human brain, paralleling the long-lasting behavioural and neurological effects of the drug. Our data on cognitive impairment in MA users echoed this finding, demonstrating impaired function in this group by MoCA assessment.

Much of the focus on MA in the literature has been placed on its neurological and behavioural aspects. Unlike ketamine, whose effects on the urinary tract and treatment modalities have been more commonly discussed, ${ }^{16}$ similar research endeavours have not been undertaken in the area of MA, even though it is a more widely abused drug. Thus, our study was an effort to investigate the clinical presentation of MA abuse on the urinary tract and compare it with ketamine abuse, another common drug of illicit use. As illustrated by our findings in the cohort, patients who used MA reported at least moderate severity of urinary symptoms by IPSS assessment. Because we studied a group of young patients with mean age 27.2 years, we conclude that the urological impact of MA abuse cannot be neglected.

In the current study, storage symptoms (particularly urinary frequency) had similar prevalence between patients who used MA and ketamine (Table 2). On assessment of storage symptoms by OABSS, patients in both groups attained similar scores to patients with overactive bladder syndrome. ${ }^{17}$ In the case of ketamine abuse, storage symptoms can be attributed to denuded mucosa and infiltration of inflammatory cells into the lamina propria of the bladder, eventually leading to chronic inflammation and fibrosis. ${ }^{5}$ It has been postulated that the storage symptoms from MA abuse can be the result of a dysfunctional dopamine pathway in detrusor control. The $\beta$ phenylethylamine core structure of MA allows it to cross the blood-brain barrier easily and to resist brain biotransformation. Furthermore, its structural similarity with monoamine neurotransmitters allows
TABLE 3. Renal function, symptom scores, and uroflowmetry of patients*

\begin{tabular}{lccc}
\hline & Ket only & MA only & P value† \\
\hline Creatinine (mmol/L) & $88.48 \pm 55.44$ & $66.83 \pm 16.92$ & 0.138 \\
Questionnaire scores & & & \\
\hline OABSS & $6.6 \pm 3.2$ & $6.1 \pm 4.1$ & 0.575 \\
\hline IIEF & $18.1 \pm 4.8$ & $16.3 \pm 5.1$ & 0.462 \\
\hline MoCA & $24.8 \pm 2.5$ & $23.6 \pm 2.9$ & 0.298 \\
\hline PUF & & & \\
\hline Symptom score & $11.1 \pm 4.7$ & $8.6 \pm 4.3$ & 0.135 \\
\hline Bother score & $6.7 \pm 2.9$ & $4.7 \pm 2.5$ & 0.036 \\
\hline Total score & $17.8 \pm 7.4$ & $13.3 \pm 6.6$ & 0.080 \\
\hline IPSS & & & \\
\hline Total score & $20.9 \pm 8.1$ & $16.1 \pm 8.9$ & 0.080 \\
\hline Quality of life score & $4.6 \pm 1.3$ & $3.9 \pm 1.7$ & 0.227 \\
\hline Uroflowmetry & & & \\
\hline Qmax (mL/s) & $16.8 \pm 11.9$ & $17.1 \pm 10.1$ & 0.819 \\
\hline VVol (mL) & $179.0 \pm 168.7$ & $191.5 \pm 190.9$ & 0.703 \\
\hline PVR (mL) & $15.1 \pm 20.2$ & $23.2 \pm 40.7$ & 0.867 \\
\hline Bladder capacity (mL) & $194.1 \pm 166.4$ & $214.7 \pm 191.5$ & 0.795 \\
\hline BEE & $86.2 \pm 23.9$ & $85.7 \pm 19.8$ & 0.843 \\
\hline
\end{tabular}

Abbreviations: BEE = bladder emptying efficiency; IIEF = International Index of Erectile Function; IPSS = International Prostate Symptom Score; Ket = ketamine; MA = methamphetamine; MoCA = Montreal Cognitive Assessment; OABSS = Overactive Bladder Symptom Score; PUF = Pelvic Pain and Urgency/Frequency; PVR = post-void residual; $\mathrm{Qmax}=$ maximal voiding velocity; $\mathrm{W} \mathrm{Vol}=$ voided volume

* Data are shown as mean \pm standard deviation

† Mann-Whitney $U$ test

amphetamines to act as competitive substrates at dopamine's membrane transporters. It also promotes dopamine release from storage vesicles. All these effects increase cytoplasmic dopamine concentrations and enhance reverse transport. ${ }^{18}$ However, long-term exposure to amphetamines may result in dopamine neuron terminal damage or loss. A post-mortem study of people who used MA chronically showed a mean $50 \%$ to $60 \%$ reduction in dopamine levels throughout the striatum. ${ }^{19}$ Another study on dopamine dysregulation reported a $25 \%$ to $30 \%$ decrease in the maximal extent of dopamineinduced stimulation of adenylyl cyclase activity in the striatum. ${ }^{20}$ These results suggested that dopamine signalling in the striatum of people who use MA chronically was impaired both presynaptically and postsynaptically. An animal study showed that a selective D1 antagonist decreased bladder capacity in rats. ${ }^{21}$ Taking Parkinson's disease, which is the result of dopaminergic neuron degeneration with the basal ganglia failing to suppress micturition, ${ }^{22}$ as a reference, the pathological dopaminergic pathway could be one of the aetiologies behind MA-related urinary symptoms. 
In our cohort, $26.7 \%$ of patients who used MA reported hesitancy during voiding, and $46.7 \%$ reported a sensation of incomplete emptying (Table 2). Case reports in the literature have drawn an association between amphetamines and urinary retention. ${ }^{23,24}$ These findings underlined the possibility that MA-related urological pathology might have multiple facets rather than purely concerning the dopaminergic axis and storage symptoms. The possible aetiology may be the increased release of norepinephrine from MA abuse, which may cause increased $\alpha$-adrenergic stimulation of the bladder neck. ${ }^{25}$ In a study of medical treatment for urinary symptoms in people who used MA, Koo et $\mathrm{a}^{26}$ reported that $\alpha$-blockers resulted in a $33 \%$ treatment success rate in terms of IPSS reduction for patients with predominant voiding symptoms. This observation could be employed as a reference for treatment options.

Patients with ketamine abuse more commonly experienced dysuria and pelvic pain. In our previous report of 319 patients with ketamine abuse, the mean PUF score was 22.2. ${ }^{16}$ In contrast, symptoms of dysuria and pelvic pain were not commonly observed in patients with MA abuse. This could be because the effects of MA on the urinary tract were more on neurology rather than local tissue destruction, resulting in less local nociceptor stimulation. Currently, there are no reports on histological assessment of urinary tract tissues in people who use MA. This would be useful to facilitate a more comprehensive investigation on the impact on MA on the urinary tract.

The relatively small sample size of our cohort limited our statistical analysis. As MA abuse has only gained popularity in recent years in our locality, and the urological sequelae of such abuse might take years before it becomes prominent and severe, the current study could act as an initial assessment highlighting the early observation of urological presentation. One of the potential limitations of our study is that the majority of the patients presenting to our clinic were not active substance abusers. At the time point of assessment, the use of a heterogeneous group of active and former abusers may introduce bias into our evaluation. However, our cohort included mostly patients with long abuse duration. Studies have demonstrated the persistent effects of drug abuse even after a period of abstinence, namely dysfunctional dopamine metabolism in patients who had used $\mathrm{MA}^{27}$ and urinary tract damage in patients who had used ketamine. ${ }^{5}$ Thus, the clinical picture captured by our study may still reflect the impact of drug abuse on the urinary tract.

In conclusion, MA is a common drug of choice for abuse in Asia. It causes urinary tract dysfunction, predominantly in the form of storage symptoms. Compared with ketamine, MA abuse was not commonly associated with dysuria or pelvic pain. In addition to the behavioural impacts of MA abuse, its urinary tract implications should not be neglected.

\section{Author contributions}

All authors had full access to the data, contributed to the study, approved the final version for publication, and take responsibility for its accuracy and integrity.

Concept or design: CH Yee, CF Ng, YH Tam.

Acquisition of data: YL Hong, PT Lai.

Analysis or interpretation of data: $\mathrm{CH}$ Yee, YL Hong.

Drafting of the article: $\mathrm{CH}$ Yee, YL Hong.

Critical revision for important intellectual content: $\mathrm{CH}$ Yee, CF Ng, YH Tam.

\section{Conflicts of interest}

As an editor of the journal, CF Ng was not involved in the peer review process of the article. Other authors have no conflicts of interest to disclose.

\section{Funding/support}

This research project was funded by the Beat Drugs Fund, The Government of the Hong Kong Special Administrative Region.

\section{Ethics approval}

Ethics committee approval was granted for the study (CREC Ref CRE-2011.454). Written informed consent was given by all participants before entering the study.

\section{References}

1. United Nations Office on Drugs and Crime. World drug report. 2018. Available from: https://www.unodc.org/ wdr2018/. Accessed 10 May 2019.

2. Chacko JA, Heiner JG, Siu W, Macy M, Terris MK. Association between marijuana use and transitional cell carcinoma. Urology 2006;67:100-4.

3. Bowles DW, O’Bryant CL, Camidge DR, Jimeno A. The intersection between cannabis and cancer in the United States. Crit Rev Oncol Hematol 2012;83:1-10.

4. Madhrira MM, Mohan S, Markowitz GS, Pogue VA, Cheng JT. Acute bilateral renal infarction secondary to cocaineinduced vasospasm. Kidney Int 2009;76:576-80.

5. Yee C, Ma WK, Ng CF, Chu SK. Ketamine-associated uropathy: from presentation to management. Curr Bladder Dysfunct Rep 2016;11:266-71.

6. Yiu-Cheung C. Acute and chronic toxicity pattern in ketamine abusers in Hong Kong. J Med Toxicol 2012;8:26770.

7. Ren Q, Ma M, Hashimoto K. Current status of substance abuse in East Asia and therapeutic prospects. East Asian Arch Psychiatry 2016;26:45-51.

8. Sun HQ, Bao YP, Zhou SJ, Meng SQ, Lu L. The new pattern of drug abuse in China. Curr Opin Psychiatry 2014;27:2515.

9. Wada K, Funada M, Shimane T. Current status of substance abuse and HIV infection in Japan. J Food Drug Anal 2013;21:S33-6.

10. Kwon NJ, Han E. A commentary on the effects of methamphetamine and the status of methamphetamine 
abuse among youths in South Korea, Japan, and China. Forensic Sci Int 2018;286:81-5.

11. Narcotics Division, Security Bureau, Hong Kong SAR Government. Central Registry of Drug Abuse SixtySeventh Report. Available from: https://www.nd.gov.hk/ en/crda_report.htm. Accessed 10 May 2019.

12. Homma Y, Yoshida M, Seki N, et al. Symptom assessment tool for overactive bladder syndrome-overactive bladder symptom score. Urology 2006;68:318-23.

13. Ng CM, Ma WK, To KC, Yiu MK. The Chinese version of the Pelvic Pain and Urgency/Frequency Symptom Scale: a useful assessment tool for street-ketamine abusers with lower urinary tract symptoms. Hong Kong Med J 2012;18:123-30.

14. Chu LW, Ng KH, Law AC, Lee AM, Kwan F. Validity of the Cantonese Chinese Montreal Cognitive Assessment in Southern Chinese. Geriatr Gerontol Int 2015;15:96-103.

15. Kolbrich EA, Goodwin RS, Gorelick DA, Hayes RJ, Stein EA, Huestis MA. Plasma pharmacokinetics of 3,4-methylenedioxymethamphetamine after controlled oral administration to young adults. Ther Drug Monit 2008;30:320-32.

16. Yee $\mathrm{CH}$, Lai PT, Lee WM, Tam YH, Ng CF. Clinical outcome of a prospective case series of patients with ketamine cystitis who underwent standardized treatment protocol. Urology 2015;86:236-43.

17. Hung MJ, Chou CL, Yen TW, et al. Development and validation of the Chinese Overactive Bladder Symptom Score for assessing overactive bladder syndrome in a RESORT study. J Formos Med Assoc 2013;112:276-82.

18. Carvalho M, Carmo H, Costa VM, et al. Toxicity of amphetamines: an update. Arch Toxicol 2012;86:1167-231.

19. Wilson JM, Kalasinsky KS, Levey AI, et al. Striatal dopamine nerve terminal markers in human, chronic methamphetamine users. Nat Med 1996;2:699-703.

20. Tong J, Ross BM, Schmunk GA, et al. Decreased striatal dopamine D1 receptor-stimulated adenylyl cyclase activity in human methamphetamine users. Am J Psychiatry 2003;160:896-903.

21. Seki S, Igawa Y, Kaidoh K, Ishizuka O, Nishizawa O, Andersson KE. Role of dopamine D1 and D2 receptors in the micturition reflex in conscious rats. Neurourol Urodyn 2001;20:105-13.

22. McDonald $\mathrm{C}$, Winge $\mathrm{K}$, Burn DJ. Lower urinary tract symptoms in Parkinson's disease: prevalence, aetiology and management. Parkinsonism Relat Disord 2017;35:8-16.

23. Worsey J, Goble NM, Stott M, Smith PJ. Bladder outflow obstruction secondary to intravenous amphetamine abuse. Br J Urol 1989;64:320-1.

24. Delgado JH, Caruso MJ, Waksman JC, Honigman B, Stillman D. Acute, transient urinary retention from combined ecstasy and methamphetamine use. J Emerg Med 2004;26:173-5.

25. Skeldon SC, Goldenberg SL. Urological complications of illicit drug use. Nat Rev Urol 2014;11:169-77.

26. Koo KC, Lee DH, Kim JH, et al. Prevalence and management of lower urinary tract symptoms in methamphetamine abusers: an under-recognized clinical identity. J Urol 2014;191:722-6.

27. Ares-Santos S, Granado N, Moratalla R. The role of dopamine receptors in the neurotoxicity of methamphetamine. J Intern Med 2013;273:437-53. 